\title{
Counseling Adult Women Survivors of Childhood Sexual Abuse: Benefits of a Wellness Approach
}

\author{
Elizabeth A. Hodges \\ Jane E. Myers
}

Adult women survivors of childhood sexual abuse may face numerous lifelong challenges. Recommended therapeutic interventions for survivors assume that the process of reliving and exploring the abuse experience leads to psychological healing. Yet such therapeutic approaches may be traumatizing for both client and counselor, and seem to be somewhat limited in affecting change in the numerous areas of concern of many survivors. Strength-based wellness counseling interventions may help survivors develop coping skills to enhance both overall quality of life and everyday functioning across multiple domains, while also providing a healthy foundation from which to explore and reframe their abuse experiences. A case example demonstrates this approach.

Sedlak (1996) reported that the incidence of childhood sexual abuse doubled between 1986 and 1993. Sexual abuse has since reached epidemic proportions, with one in four women worldwide experiencing sexual violence from an intimate partner and as many as one-third of all adolescent girls reporting forced encounters as their first sexual experience (Krug, Dahlberg, Mercy, Zwi, \& Lozano, 2002). The American Academy of Child and Adolescent Psychiatry (2004) noted that statistics concerning childhood sexual abuse (CSA) vastly underestimate prevalence because most children are afraid to report abuse and the legal procedures for validating abuse are at best cumbersome.

Still, the reported rates are staggering: For example, in $2000,67 \%$ of all sexual assault victims were juveniles, $34 \%$ were younger than 12 , and about $15 \%$ (one in seven) were younger than 6 (Bureau of Justice Statistics, 2000). The National Center for Victims of Crime (2007) reported that girls are victimized at least three times more often than boys, and one in four adolescent girls will experience CSA before reaching 18 . The consequences include serious, perva-

Elizabeth A. Hodges and Jane E. Myers are affiliated with the University of North Carolina at Greensboro. Correspondence concerning this article should be addressed to Elizabeth A. Hodges, M. A., NCC. The University of North Carolina at Greensboro, Dept. of Counseling \& Educational Development, PO Box 26171, 222 Curry, 1109 Spring Garden Street, Greensboro, NC 27402-6171. E-mail: eahodge2@uncg.edu. 
sive, and lifelong damage to physical and mental health and functioning, leading Noll (2008) to state unequivocally that "the covariation between childhood abuse and maldevelopment is currently above dispute" (p. 1).

A number of authors have noted the challenges mental health counselors face in working with adult women survivors of CSA, such as self-mutilation, eating disorders, dissociative disorders, and antisocial behavior (Wise, Florio, Benz, $\&$ Geier, 2007). Further, listening to the stories of trauma survivors places the professional at risk of empathy fatigue (Stebnicki, 2008) and secondary trauma (Etherington, 2000; Lev-Wiesel, 2008). Treatment for CSA survivors requires multiproblem intervention strategies because of the sheer number of symptom possibilities (Lev-Wiesel), as well as peer supervision for the counselor to promote personal self-care and attention to boundary issues (Stebnicki). Typical strategies used include cognitive-behavioral, trauma-focused, and emotionfocused approaches (Wise et al.). Lev-Wiesel reviewed research on interventions for adult women CSA survivors and concluded that such interventions require unique approaches because the core issues relate to the separation of body and soul and the perception of the body as "worthless, weak, and helpless, meaning there is no hope for a better future" (p. 671). The integration of body and soul is the goal of wellness counseling interventions (Carney, 2005; Myers \& Sweeney, 2005c); however, wellness approaches have not yet been applied to issues specific to adult women CSA survivors.

The results of several recent outcome studies using wellness counseling suggest that these interventions can help increase holistic wellness and foster the integration of body, mind, and spirit (see Myers \& Sweeney, 2008; Tanigoshi, Kontos, \& Remley, 2008; Villalba \& Myers, 2008). Although wellness approaches have not been used with trauma survivors, we propose that holistic, strength-based interventions may be useful to help these clients de-pathologize their self-perceptions, provide them with a positive focus for growth, and help them build a healthy foundation from which to explore and heal from their experiences of abuse.

Following a brief review of characteristics of adult women CSA survivors and traditional approaches to treatment, a counseling-based wellness model is presented and used as a foundation for exploring interventions with adult women survivors. A case example demonstrates the application of this approach. Female survivors are the focus here based on the higher incidence of abuse in this population and the greater likelihood that they will seek treatment (Finklehor, 1994). Implications for mental health counselors and for outcomebased research are explored.

\section{Characteristics of Adult Women CSA Survivors}

Adult women CSA survivors present in counseling with a wide variety of symptoms and symptom clusters. There is some evidence that the symptom 
clusters are related to factors such as date of onset, duration of abuse, ages at which abuse occurred, and whether the abuse included violence or threats of violence (Loeb et al., 2002). Regardless of the exact nature of the abusive incidents, these clusters typically include mental, emotional, relational, and trauma-response issues. Symptom clusters related to mental health include psychiatric disorders common to adult women CSA survivors,, who have a two to four times increased risk for a large number of psychiatric disorders, including depression, anxiety, phobias, eating disorders, and substance abuse (Lundqvist, Svedin \& Hansson, 2004). In fact, consistently found in research on adult women CSA survivors are higher levels of depression than in women without histories of sexual abuse (Cukor \& McGinn, 2006; Meston, Rellini, \& Heiman, 2006; Schilling, Aseltine, \& Gore, 2007).

Emotional symptoms common to women CSA survivors include social maladjustment, self-blame, anger, low self-esteem, self-destruction, and anxiety (Kessler, White, \& Nelson, 2003; Ullman, 2006). Women survivors are likely to experience challenges in five major areas of emotional functioning: trust, safety, intimacy, self-esteem, and control (Shipherd, Street, \& Resick, 2006). Further, women survivors may experience disdain for their own bodies (Svedin, Back, \& Soderback, 2002) and dysfunctional sexual feelings (Vandeusen \& Carr, 2003). There is a close connection between such emotional symptoms and relational symptoms.

Adult women CSA survivors reported more relational difficulties, especially in relationships with men and partners (Loeb et al., 2002; Svedin et al., 2002), and problems in sexual functioning are not uncommon. Loeb et al. reviewed the literature on the sexual functioning of adult women CSA survivors and noted that problems range from low sexual desire and arousal to an inability to tolerate touch or to experience orgasm. Women survivors also reported other interpersonal issues, such as higher levels of negative sexual affect (Meston et al., 2006); lower levels of perceived emotional support from partners (Schilling et al., 2007); and feelings of betrayal, powerlessness, and stigmatization in relationships (Vandeusen \& Carr, 2003). Their difficulties in interpersonal relationships and social adjustment also include an inability to trust others, feelings of isolation, and feelings of insecurity in relationships (Loeb et al.; Svedin et al.).

Another symptom cluster for adult women CSA survivors relates to trauma symptoms, often described in terms of posttraumatic stress disorder (PTSD). The Diagnostic and Statistical Manual of Mental Disorders, Fourth Edition, Text Revised (DSM-IV-TR; American Psychiatric Association, 2000) identifies PTSD as a disorder resulting from exposure to a traumatic event and characterized by re-experiencing aspects of the trauma, avoidance of reminders of the trauma, and symptoms of hyperarousal. Posttraumatic stress responses are characteristic of women survivors and may manifest as disassociation, sleep disturbances, memory problems, irrational guilt, or an intensification of 
symptoms when exposed to situations or stimuli similar to the original trauma event (Kessler et al., 2003; Risser, Hetzel-Riggin, Thomsen, \& McCanne, 2006; Ullman, 2007).

CSA survivors often report physical difficulties in addition to mental, emotional, and relational challenges. Lundqvist et al. (2004) reported that annual health care costs for adult women survivors were \$245 more than for women who had no history of CSA; other researchers have reported that the higher health care costs are related to increased numbers of doctor visits (Hulme, 2000; Newman et al., 2000). Women survivors are also more likely to report somatic difficulties, such as cardiopulmonary, female reproduction, gastrointestinal tract, pseudoneurologic, and sexual symptoms (Dickinson, deGruy, Dickinson, \& Candib, 1999; Modestin, Furrer, \& Malti, 2005). The plethora and severity of symptoms and symptom clusters require multiple and broadbased approaches to mental health counseling.

\section{Mental Health Counseling Interventions}

Although researchers have established the long-term mental and physical health problems resulting from CSA, there is significant variation in women's survival experiences: some survivors may experience few to no negative symptoms; others may experience significant impairment in multiple areas of life (Davis \& Petretic-Jackson, 2000). Therapists working with women survivors will thus likely encounter significant variation in symptom presentation and level of distress. Considering the range of possible symptoms, it is no surprise that successful treatment interventions with CSA survivors are varied and longterm. Individual, group, and family counseling and cognitive-behavioral interventions have all been shown to be effective with some clients (Kessler et al., 2003; Lubin, 2007); however, personal improvements in sessions are difficult to transfer to daily life and sustain over time.

Although there is little agreement in the literature on the "best" therapeutic approach (Wise et al., 2007), one of the most common interventions with adult women CSA survivors is trauma-focused, or exposure-based, treatment, where the sexual abuse experience is reviewed in some way (Cloitre, StovallMcClough, \& Levitt, 2004; Follette \& Ruzek, 2006; Putman, 2009). Traumafocused interventions are based on the notion that the meaning "attach[ed] to the abuse, as well as the personal impact, is imbedded in the details of the experience" (Putman, p.83), and therefore requires in-depth review of the abuse experience. In a meta-analysis of trauma-focused therapy interventions, including individual and group modalities, Martsolf and Draucker (2005) stated, "Abuse-focused psychotherapy for adults who were sexually abused as children is generally beneficial" (p. 817). However, although trauma-focused therapies seemed to be more effective in reducing depression and trauma-specific symptoms, they did not result in consistent improvements in the interpersonal 
or social functioning symptoms (Cloitre et al.; Martsolf \& Draucker) experienced by adult women CSA survivors.

The process of trauma-focused therapy requires that counselors be "prepared to listen to everything, however horrifying or sad" (Putnam, 2009, p. 83) as clients are encouraged to retell traumatic experiences continuously throughout the counseling process. Hearing stories of trauma can result in secondary trauma ("vicarious traumatization") for the mental health counselor (Etherington, 2000; Maidenberg, 2003). One possible outcome is counter-transference in the counselor, which may manifest itself as identification with the victim, rescuer, or abuser (Etherington). As a result, counselors may lose confidence in their counseling abilities, may even minimize the impact of the abuse, or may lose awareness or recognition of the clients' strengths (Etherington; Herman, 1997).

Counseling interventions like trauma-focused therapy presuppose that the focus of therapy with women survivors of CSA is the trauma experience and that reviewing the experience is necessary for the client to improve psychologically. However, this focus is limiting; researchers have reported that during times of distress, individuals have a great capacity for posttraumatic growth (Calhoun \& Tedeschi, 1998). Focusing primarily on the trauma itself neglects the individual's growth potential and the positive effect posttraumatic growth has on psychological distress (Calhoun \& Tedeschi). Researchers have reported that perceived growth on the part of a survivor of CSA may enhance positive feelings and feelings of self-efficacy (Lev-Wiesel, Amir, \& Besser, 2005). Similarly, researchers have also reported that, with adult survivors of CSA, mastering tasks resulted in the development of resiliency (Flynn, 2003). Therefore, fostering positive growth in adult women CSA survivors is an appropriate therapeutic goal: posttraumatic growth increases positive feelings of self, self-efficacy, and resiliency, which lay the foundation for continued improvement in other areas of life.

The lack of a firm foundation for positive growth in traditional approaches to therapy with adult women CSA survivors undermines the ability of both client and counselor to perceive and use strengths to create and sustain change, both within sessions and in the client's daily life. In contrast, wellness-focused interventions offer clients a positive lens for viewing their strengths and strategies for using those strengths to cope with the issues created by their sexual abuse history. Wellness-focused interventions validate the individual and the fact that the important thing is not why the individual survived but how. Despite the potential for positive growth, researchers have neglected to investigate wellness interventions with adult women CSA survivors (CSA-S). To understand how to implement such interventions, a wellness model based in counseling is described and a case example presented. 


\section{The Indivisible Self Model of Wellness}

Researchers have proposed several models of wellness with foundations in medicine, public health, and counseling (see Myers \& Sweeney, 2005c). All share the inclusion of mental, emotional, social, vocational, cognitive, and spiritual aspects of well-being. The Indivisible Self model (IS-Wel; Myers \& Sweeney, 2005c) is grounded in Adlerian individual psychology. It emphasizes the holistic nature of human functioning as central to understanding wellness. This model is a good fit for counselors working with CSA-S due to the pervasive impact of abuse experiences on development and aspects of behavior.

Using structural equation modeling, Myers and Sweeney (2005a, 2005c) developed the IS-Wel model (see Figure 1) and discovered the self at the center of wellness. Consistent with Adlerian theory (Sweeney, 2009), this self is indivisible, and all its parts are interactive and have a reciprocal influence. Changes in any one area of wellness affect all other areas, and such changes can be in positive as well as negative directions. For example, a client who, with the help of a wellness intervention, begins and sustains an exercise program can learn that she actually has control over an important aspect of her physical self. Through mental health counseling, the client learns that she can also exert control over other aspects of her life, such as self-care, intellectual development, or self-esteem. Alternatively, a client who begins drinking to cope with negative memories of abuse, thus engaging in negative self-care, may as a consequence experience declines in all aspects of wellness. The importance of this perspective for professional counselors lies in our ability to focus interventions on any component of wellness with the anticipation that positive benefits will accrue in other areas.

Figure 1. The Indivisible Self: An Evidence-Based Model of Wellness

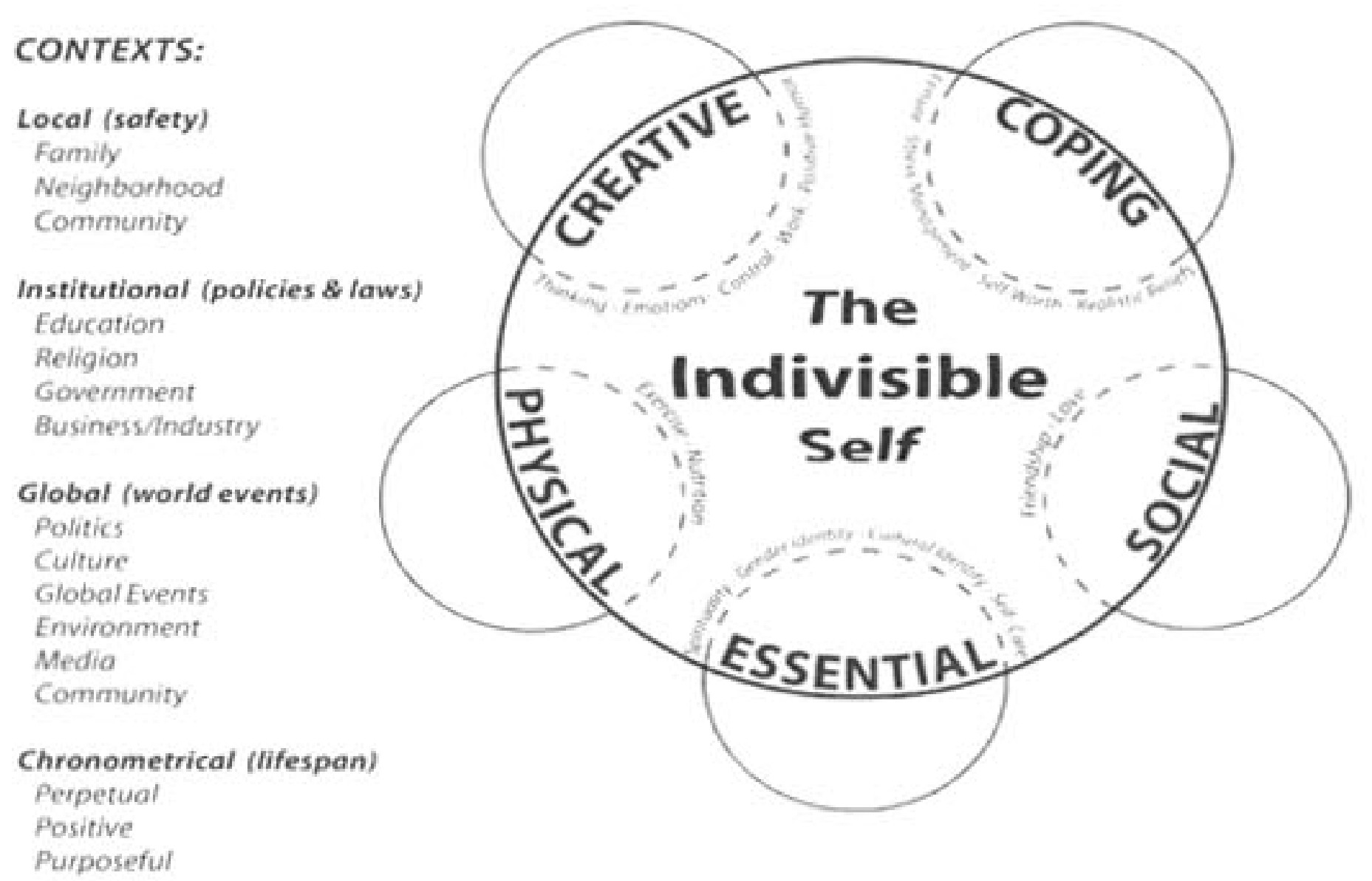

Copyright $\odot$ T.J. Sweeney, and J.E. Myers, 2003; 2-009. Reprinted with permission. All rights reserved. 
Surrounding the indivisible self in the IS-Wel model are five second-order factors of the self: Creative, Coping, Social, Essential, and Physical (Myers \& Sweeney, 2005c). Each factor is comprised of unique subfactors; the model has a total of 17 subfactors. Myers and Sweeney (2005c) described the factors and subfactors as follows:

The Creative Self is that part of an individual that makes him or her unique among others. Subfactors are thinking, emotions, control, positive humor, and work.

The Coping Self is comprised of four subfactors: realistic beliefs, stress management, self-worth, and leisure. These are the essential pieces that help an individual cope and then transcend negative life events.

The Social Self has only two parts: friendship and love. These are not distinguishable but rather thought of as on a continuum.

The Essential Self is comprised of the subfactors that affect how one makes meaning in life: spirituality, self-care, gender identity, and cultural identity.

The Physical Self is comprised of all biological and physiological processes of human functioning, such as exercise and nutrition (pp. 32-33).

Personal responsibility and choice are implicit in the wellness philosophy. From this perspective, clients realize the importance of choices, the fact that choices occur throughout each day in large and small ways, and that each choice is self-reinforcing and in a positive direction contributes to growth, much as a snowball gathers both mass and momentum as it moves in a targeted direction. An emphasis on small choices, reinforcement of small decisions, and the cumulative nature of choices is thus inherent in the wellness counseling paradigm. Clients are also encouraged to choose only one or two areas for change to promote focus and increase the potential for observable change. The therapist then reinforces and reframes these observable changes in terms of the clients' strengths.

Myers and Sweeney (2005c) proposed a four-step approach to working with clients based on the IS-Wel model: (1) introduction of the wellness model; (2) formal and informal assessment of its components; (3) intentional interventions to enhance wellness; and (4) evaluation, follow-up, and recycling through the four steps. Assessing wellness dimensions can be formal, through tools like the Five-Factor Wellness Inventory (Myers \& Sweeney, 2005b), or informal, through basic scaling with each factor (Myers \& Sweeney, 2005b). During the intervention stage the client identifies one or at most two areas to work on and counselor and client together construct a personal wellness plan (Myers \& Sweeney, 2005c). The final stage focuses on assessing progress, providing 
follow-up, and possibly beginning the process again with another area of wellness (Myers \& Sweeney, 2005c).

\section{Using the IS-Wel Model with a CSA Survivor}

The following example describes a fictitious client with presenting issues and personal characteristics common in adult women CSA survivors. We chose to create a composite client rather than use an actual client to protect confidentiality and to allow multiple issues to be presented and discussed from a wellness perspective. After describing the client, we describe a wellness intervention based on the Myers \& Sweeney (2005a, b, c) four-phase model.

The Client. E. J., a Caucasian, was 41 when she began counseling. She had been married for 17 years and had two children, a son, 14, and a daughter, 11 . Her husband was a CPA working in a medium-sized company. E. J. worked as office manager for a local doctor. A friend referred her to counseling after she disclosed feelings of hopelessness and lack of control over her life.

E.J. had three close female friends who knew about how she was sexually abused by a male relative at the age of 8 . They provided significant support for her. Though she struggled at times with being emotionally vulnerable with friends, E.J. believed her friendships are what kept her going. Similarly, E.J. struggled with opening up emotionally with her husband. Although this produced distance in their relationship, she noted that her husband was a major source of support.

E.J. had previously been treated for depression. Among several physical health problems, she had high blood pressure and high cholesterol, and was taking medications for both. She was also very overweight and reported low energy.

Considering E.J.'s presenting concerns, the therapist thought that a wellness intervention would empower her and help her regain feelings of control and minimize feelings of hopelessness. The wellness intervention would also promote positive growth for her. All these benefits would promote E.J.'s self-efficacy and coping skills so that, if she desired, she could explore the sexual abuse experiences in future counseling sessions. However, because E.J. presented with specific concerns, these had to be the focus of the therapy and the wellness intervention. If her concerns changed over time, the therapist would assess these changes and if necessary modify the treatment plan.

Intervention Phase I: Introduction of the Model. The therapist gave E.J. a copy of the Indivisible Self model and a definition of each of its main components. As she and the therapist discussed each component, she was encouraged to ask questions and think about the meaning of each in her life. The therapist encouraged her to think about how well she felt in relation to each area, and which areas were most important to her. Finally, the therapist asked E.J. to describe the main parts of the model to be sure her understanding of the 
components and their interaction was accurate. The therapist also facilitated E.J.'s exploration of the meaning of personal choice and responsibility in relation to her general wellness and in relation to specific wellness factors that were of concern to her.

Intervention Phase II: Assessment of Wellness. E.J. completed a paper and pencil measure, the Five Factor Wellness Inventory (5F-Wel; Myers \& Sweeney, 2005b), which provided a profile based on an overall wellness score and scores on the five wellness factors (see Figure 2). Scores on each scale on this measure can range from 25 to 100. Mean scores reported by Myers and Sweeney (2005b) range from about $75-85$ for general adult populations across the scales, with scores on Realistic Beliefs typically being among the lowest.

E. J.'s wellness profile indicated low overall Wellness (65). This global factor indicated that she likely experienced challenges in many wellness areas, so interpretation of her profile focused on identifying patterns of both low and higher scores. Because high scores indicate strengths, one goal was to help her recognize and use her strengths to begin to change in a positive direction.

E.J.'s lowest scores were in Physical Self (53) and Essential Self (55). Contributing substantially to the former were low scores in both nutrition (45) and exercise (60). Her score on the Essential Self was interesting in that Spirituality was moderately high (75) whereas Self-Care (40) and Gender Identity (50) were significantly lower, which pulled down the total score on this factor. By looking at the third-order factor structure, we were able to identify Spirituality as a strength.

E.J. had slightly higher scores for the Coping Self (63) and Creative Self (71) factors, and her highest score was in Social Self wellness (88).

The therapist asked E.J. to review her scores and reflect on their accuracy based on her understanding of what the factors meant in relation to her own lifestyle and life challenges. She agreed with most of the scores, though she was concerned that her Self-Care and Realistic Beliefs scores were so low. As for the others, she said, "That pretty much describes me."

Intervention Phase III: Development and Implementation of a Personal Wellness Plan. E.J.'s wellness profile indicated challenges in numerous areas. Her major strengths were relationships, especially friendship; her faith; and intellectual aspects, such as curiosity for learning and problem-solving abilities. In drafting her wellness plan, we sought to help her find ways to change areas of lower wellness in part by mobilizing her areas of strength. Multiple interventions could address E.J.'s wellness challenges, but she identified two areas that she considered most important in terms of her current life situations, feelings, and challenges: Realistic Beliefs, a component of the Coping Self; and SelfCare, a component of the Essential Self. For each area, she was able to identify strengths that could be mobilized to enhance the likely success of her plan (see below). She was also able to articulate the importance of her support system to 
Figure 2. Profile of Wellness Scores for E.J. on the Five Factor Wellness Inventory

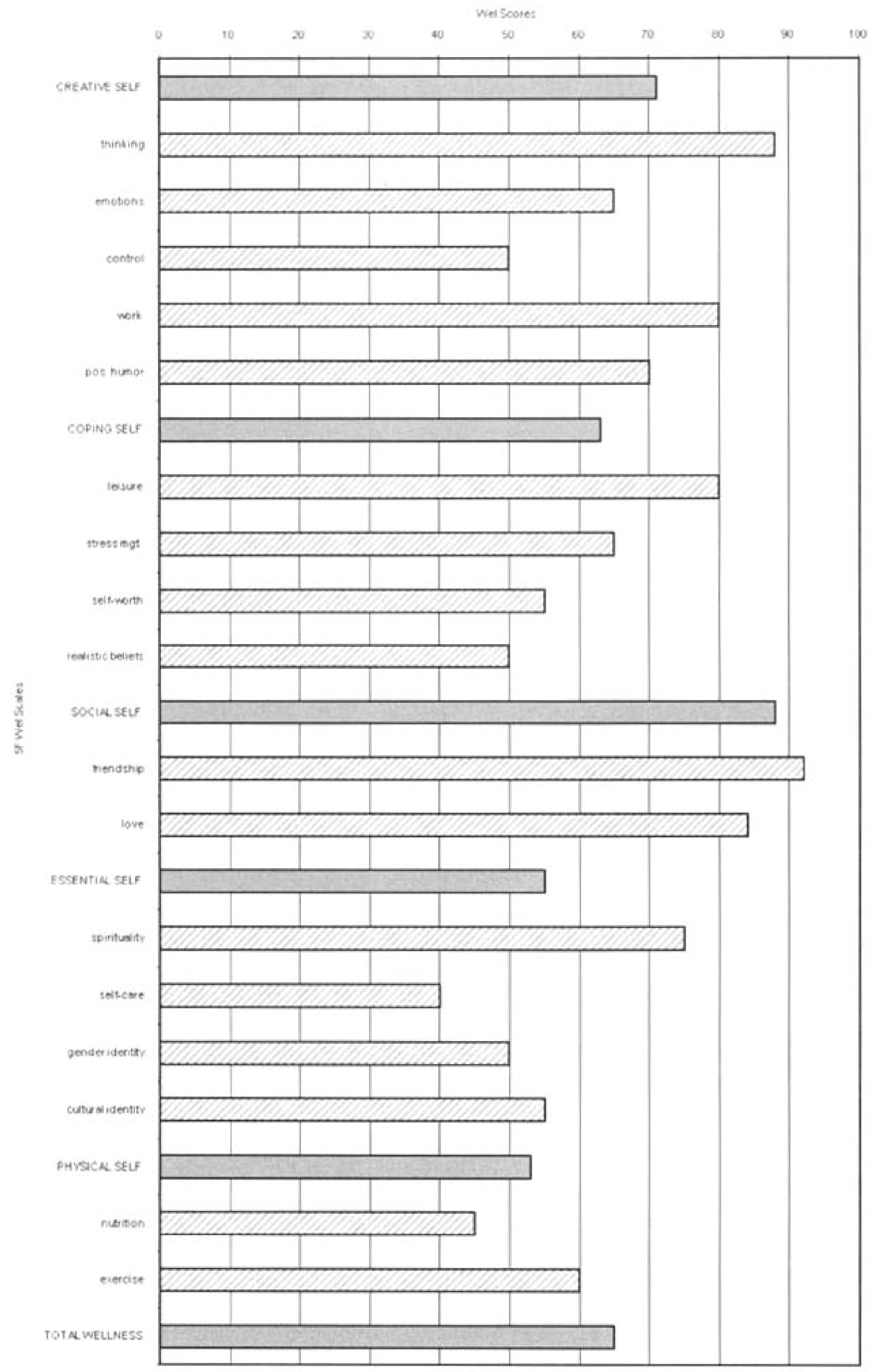


her overall wellness, and she was encouraged to find ways to involve her friends and husband as she designed concrete strategies for change.

According to the Indivisible Self model of wellness, self-care focuses on preventive measures responsible for increasing self-care and safety, such as regular medical care, wearing seat belts, using prescribed drugs appropriately, avoiding the use of illegal drugs and tobacco, moderating use of alcohol, and getting adequate sleep. E.J. had a number of positive self-care habits but reported high use of alcohol as a way of coping with negative feelings and regularly having difficulty sleeping as a consequence. Self-care interventions targeted moderating alcohol use and improving sleep.

Initially E.J. resisted changing her alcohol use because she noted no problems with her current level of consumption. She reported not being an alcoholic and thought that having a few glasses of wine to relax at night was not a problem. Using a scaling activity, the therapist asked E.J. to indicate how important sleep was in her life on one side of a scale. She identified it as highly important and discussed how she had significant difficulty performing at work because of her lack of sleep. The therapist also encouraged her to recall a time when she slept well. As she talked about it, it seemed to the therapist that her quality of life was generally higher then. E.J. reported that it was in fact better then and that she knew sleep was one of the areas she really wanted to improve. The therapist then asked E.J. to indicate the importance of alcohol use on the other side of the scale. E.J. noted she likes to drink but can see how, if related to sleep, it is less important than getting a good night's rest. From here the therapist and E.J. constructed ways to moderate her alcohol use and other helpful ways to increase the amount and quality of sleep.

The aspects of realistic beliefs most salient to E.J. were difficulty with irrational or distorted thoughts about herself, controlling thoughts like "shoulds," and unrealistic expectations of herself and others. The counselor and E.J. worked to dispute some of these thoughts in session using cognitive interventions, and E.J. worked outside of session on thought-stopping and disputing irrational thoughts. She also invested more energy into determining appropriate and realistic expectations for herself and others. E.J. wrote in a journal about these outside of session and processed her journals in session to help her develop realistic expectations that were also satisfying.

Intervention Phase IV: Evaluation and Follow-up. The wellness plan for E.J. called for specific work on two wellness areas which E.J. reported wanting to change and for which she scored low on the 5F-Wel. Through successful self-change in these two areas, E.J. began to report feeling a greater sense of control in her life because she was able to improve both her sleep and disruptive thought patterns. The improvement in sleep gave E.J. the much-needed energy to begin an exercise routine and plan healthier meals.

The increased wellness in the two targeted areas together had a significant 
impact on other wellness areas. These included positive changes in stress management and feelings of self-worth. E.J.'s husband and children noted the positive improvements and all began working together on planning meals and spending time together being active. E.J.'s friends noticed the improvements as well. As E.J.'s wellness improved, her ability to manage negative thoughts effectively related to the past abuse increased significantly. She reached out more to her family in times of stress and reported feeling greater support from them. E.J.'s improvement in wellness gave her the strength and coping skills necessary to effectively weather these stressful times.

Finally, and perhaps most important in relation to sexual abuse issues, E.J. was able to use the strengths developed through wellness counseling interventions to begin to describe, reframe, and heal from her abuse experiences. Rather than focusing solely on the trauma, she was able to identify and make daily choices in relation to positive wellness behaviors. These positive changes helped her begin to see that there is more to her than her sexual abuse history.

\section{CONCLUSION}

CSA has a significant and pervasive impact on individuals, producing a variety of mental, emotional, relational, physical, and trauma symptoms. Most therapeutic interventions for CSA focus primarily on reliving or retelling, in great detail, the sexual abuse experience. However, many clients lack a positive sense of self, an internal locus of control, and an ability to view the abuse as only part of who they are rather than the defining elements. Through a focus on wellness factors, therapists can help adult women CSA survivors recognize their strengths and use them both in and outside of sessions to create and sustain positive lifestyle change. As demonstrated in the example, helping clients experience positive outcomes of wellness choices is empowering and facilitates their ability to invest in and cope with the healing process. Considering the multiple challenges many survivors bring to counseling, these outcomes are extremely important.

Researchers have not looked at the effectiveness of interventions based on the IS-Wel with adult women survivors of CSA. However, as the case study suggests, a wellness-based intervention may increase self-efficacy, resiliency, and awareness of healthy coping skills, resulting in positive changes in everyday functioning. Such changes are inherently helpful to the survival process and can offer survivors valuable tools with which to approach future experiences.

Despite the benefits, some contraindications may apply to wellness interventions with adult women CSA survivors, who may present with any number of symptoms. Therapists need to consider symptom presentation and prioritize the goals for therapy accordingly. For example, a woman who presents with severe 
depression and suicidal ideation will need to address these first. However, once safety is established, therapists and clients can incorporate a wellness intervention into a range of treatment options; as Calhoun and Tedeschi (1998) reported, positive growth can occur simultaneously with distressing emotions. As with any therapeutic intervention, the therapist must continually assess the client's experience with the intervention and alter interventions when necessary.

Much of the research on CSA-S focuses on clinical symptoms. Incorporating a wellness-oriented, strengths-based approach into research with this population can improve our understanding of survivors and thus inform clinical practice. Further, much clinical practice with CSA-S focuses on the sexual abuse experience rather than on identifying life strengths and coping behaviors in response to events including and beyond the abuse itself. Additional research will help inform wellness-focused counseling with CSA-S and determine what survivor characteristics are more favorable to a wellness focus. Finally, research comparing therapeutic outcomes of CSA-S receiving trauma-focused therapy and of CSA-S receiving wellness-focused therapy will validate fully the clinical perspectives and experiences presented here.

\section{REFERENCES}

American Academy of Child and Adolescent Psychiatry. (2004). Advocates for Youth, Childhood sexual abuse: An overview. Washington: Author.

American Psychiatric Association. (2000). Diagnostic and statistical manual of mental disorders $D S M-I V-T R$ ( Fourth ed.). Washington: Author.

Bureau of Justice Statistics. (2000). Sexual assault of young children as reported to law enforcement: Victim, incident, and offender characteristics. Washington: U. S. Department of Justice.

Calhoun, L. G., \& Tedeschi, R. G. (1998). Beyond recovery from trauma: Implications for clinical practice and research. Journal of Social Issues, 54, 357-371.

Carney, J. L. (2005). Wellness counseling in community mental health agencies In J. E. Myers \& T. J. Sweeney (Eds.), Counseling for wellness: Theory, research, and practice (pp. 234-244). Alexandria, VA: American Counseling Association.

Cloitre, M., Stovall-McClough, K.C., \& Levitt, J.T. (2004). Treating life-impairing problems beyond PTSD: Reply to Cahill, Zoellner, Feeny, and Riggs. Journal of Consulting and Clinical Psychology, 72, 549-551.

Cukor, D., \& McGinn, L.K. (2006). History of child abuse and severity of adult depression: The mediating role of cognitive schema. Journal of Child Sexual Abuse, 15, 19-34.

Davis, J.L., \& Petretic-Jackson, P.A. (2000). The impact of child sexual abuse on adult interpersonal functioning: A review and synthesis of empirical literature. Aggression and Violent Behavior, 5, 291-328.

Dickinson, L.M., deGruy, F.V., Dickinson, P., \& Candib, L.M. (1999). Health-related quality of life and symptom profiles of female survivors of sexual abuse. Archives of Family Medicine, 8, $35-43$.

Etherington, K. (2000). Supervising counselors who work with survivors of childhood sexual abuse. Counselling Psychology Quarterly, 13, 377-389.

Finkelhor, D. (1994). The international epidemiology of child sexual abuse. Child Abuse \& Neglect, $18,409-418$. 
Flynn, L. C. (2003). Soul sifting and the process toward resiliency in response to childhood sexual abuse. Dissertation Abstracts International: Section B: The Sciences and Engineering, 64(3-B), 1488.

Follette, V.M., \& Ruzek, J.I. (2006). Preface. In Follette, V.M., \& Ruzek, J.I. (Eds). Cognitive behavioral therapies for trauma. New York: The Guilford Press.

Herman, J. (1997). Trauma and recovery: The aftermath of violence-from domestic violence to political terror. New York: Basic Books.

Hulme, P.A. (2000). Symptomatology and health care utilization of women primary care patients who experienced childhood sexual abuse. Child Abuse \& Neglect, 24, 1471-1484.

Kessler, M. R. H., White, M. B., \& Nelson, B. S. (2003). Group treatments for women sexually abused as children: A review of the literature and recommendations for future outcome research. Child Abuse \& Neglect, 27, 1045-1061.

Krug, E. G., Dahlberg, L.L., Mercy, J. A., Zwi, A. B., \& Lozano, R. (Eds.). (2002). World report on violence and health. Geneva, Switzerland: World Health Organization.

Lev-Wiesel, R. (2008). Child sexual abuse: A critical review of intervention and treatment modalities. Child and Youth Services Review, 30, 665-673.

Lev-Wiesel, R., Amir, M., \& Besser, A. (2005). Posttraumatic growth among female survivors of childhood sexual abuse in relation to perpetrator identity. Journal of Loss and Trauma, 10, 7-17.

Loeb, T., Williams, J., Carmona, J., Rivkin, I., Wyatt, G., Chin, D., \& Asuan-O’Brian, A. (2002). Child sexual abuse: Associations with the sexual functioning of adolescents and adults. Annual Review of Sex Research, 13, 307-345.

Lubin, H. (2007). Group and individual therapy for childhood sexual abuse survivors. International Journal of Group Psychotherapy. 57, 257-262.

Lundqvist, G., Svedin, C. G., \& Hansson, K. (2004). Childhood sexual abuse: Women's health when starting in group therapy. Nordic Journal of Psychiatry, 58, 25-32.

Maidenberg, M.P. (2003). Considerations in supervision: Conducting child sexual abuse survivor groups. The Clinical Supervisor, 22, 81-97.

Martsolf, D.S., \& Draucker, C.B. (2005). Psychotherapy approaches for adult survivors of childhood sexual abuse: An integrative review of outcomes research. Issues in Mental Health Nursing, 26, 801-825.

Meston, C.M., Rellini, A.H., \& Heiman, J.R. (2006). Women's history of sexual abuse, their sexuality and sexual self-schemas. Journal of Consulting and Clinical Psychology, 74, 229-236.

Modestin, J., Furrer, R., \& Malti, T. (2005). Different traumatic experiences are associated with different pathologies. Psychiatric Quarterly, 76, 19-32.

Myers, J. E., \& Sweeney, T. J. (2008). Wellness counseling: The evidence base for practice. Journal of Counseling \& Development, 86, 482-493.

Myers, J. E., \& Sweeney, T. J. (Eds.). (2005a). Counseling for wellness: Theory, research, and practice. Alexandria, VA: American Counseling Association.

Myers, J. E., \& Sweeney, T. J. (2005b). Manual for the Five Factor Wellness Inventory. Palo Alto, CA: Mindgarden, Inc.

Myers, J. E., \& Sweeney, T. J. (2005c). The indivisible self: An evidence-based model of wellness. The Journal of Individual Psychology, 61, 269-279.

National Center for Victims of Crime. (2007). Childhood sexual abuse. Retrieved December 1, 2008, from http://www.ncvc.org/ncvc/main.aspx?dbName=DocumentViewer\&DocumentID= 32315

Newman, M.G., Clayton, L., Zuellig, A., Cashman, L., Arnow, B., Dea, R., \& Taylor, C.B. (2000). The relationship of childhood sexual abuse and depression with somatic symptoms and medical utilization. Psychological Medicine, 30, 1063-1077. 
Noll, J. (2008). Sexual abuse of children: Unique in its effects on development? Child Abuse and Neglect, 32, 603-605.

Putnam, S. (2009). The monsters in my head: Posttraumatic stress disorder and the child survivor of sexual abuse. Journal of Counseling \& Development, 87, 80-89.

Risser, H.J., Hetzel-Riggin, M.D., Thomsen, C.J., \& McCanne, T.R. (2006). PTSD as a mediator of sexual revictimization: The role of reexperiencing, avoidance, and arousal symptoms. Journal of Traumatic Stress, 19, 687-698.

Schilling, E.A., Aseltine, R.H., \& Gore, S. (2007). Young women's social and occupational development and mental health in the aftermath of child sexual abuse. American Journal of Community Psychology, 40, 109-124.

Sedlak, B. (1996). Executive summary of the third national incidence study of child abuse and neglect. Washington: U. S. Department of Health and Human Services, Administration for Children and Families.

Shipherd, J. C., Street, A. E., \& Resick, P. A. (2006). Cognitive therapy for posttraumatic stress disorder. In Follette, V.M., \& Ruzek, J.I. (Eds). Cognitive behavioral therapies for trauma, New York: The Guilford Press.

Stebnicki, M. (2008). Empathy fatigue: Healing the mind, body, and spirit of professional counselors. New York: Springer.

Svedin, C., Back, C., \& Soderback, S. (2002). Family relations, family climate and sexual abuse. Nordic Journal of Psychiatry, 56, 355-362.

Sweeney, T. J. (2009). Adlerian counseling and psychotherapy: A practitioner's approach. Philadelphia: Taylor Francis/Routledge.

Tanigoshi, H., Kontos, A. P., \& Remley, T. (2008). The effectiveness of individual wellness counseling on the wellness of law enforcement officers. Journal of Counseling \& Development, 86, 64-74.

Ullman, S. (2006). Relationship to perpetrator, disclosure, social reactions, and PTSD symptoms in child sexual abuse survivors. Journal of Child Sexual Abuse, 16, 19-36.

Vandeusen, K. M., \& Carr, J. L. (2003). Recovery from sexual assault: An innovative two-stage group therapy model. International Journal of Group Psychotherapy, 53, 201-223.

Villalba, J. A., \& Myers, J. E. (2008). The effectiveness of wellness-based classroom guidance in elementary school settings: A pilot study. Journal of School Counseling, 6, http://www.jsc.montana.edu/articles/v6n9.pdf

Wise, S., Florio, D., Benz, D. R., \& Geier, P. (2007). Ask the experts: Counseling sexual abuse survivors. Annals of the American Psychotherapy Association, 10, 18-21. 